\title{
Calcification of polyurethanes implanted subdermally in rats is enhanced by calciphylaxis
}

\author{
Ravi R. Joshi, ${ }^{1}$ Thomas Underwood, Jack R. Frautschi, ${ }^{1}$ Richard E. Phillips, Jr., ${ }^{1}$ Frederick J. Schoen, ${ }^{3}$ and \\ Robert J. Levy',* \\ ${ }^{1}$ Department of Pediatrics, Communicable Diseases, and Pharmaceutics, The University of Michigan, Ann Arbor, \\ Michigan 48109; ${ }^{2}$ CarboMedics, 1300-B. East Anderson Lane, Austin. Texas 78752-1793; ' Departments of Pathology, \\ Brigham and Women's Hospital and Harvard Medical School, 75 Francis Street. Boston, Massachusetts 02115
}

Calcification complicates the use of the polymer polyurethane in cardiovascular implants. To date only costly experimental circulatory animal models have been useful for investigating this disease process. In this paper we report that polyurethane calcification in rat subdermal implants is enhanced by overdosing with a vitamin-D analog. The calcification-prone state, known as calciphylaxis, was induced in 4-week old rats by oral administration of a vitamin$\mathrm{D}$ analog, dihydrotachysterol. We studied two commercially available polyurethanes (Biomer ${ }^{\circledR}$ and Mitrathane ${ }^{\circledR}$ ) and two proprietary polyurethanes (PEU-2000 and PEU-100). PEU-100 is unique because it is derivatized with ethanehydroxy-bisphosphonate (EHBP) for calcification resistance. Polyurethane calcium and phosphate levels and morphological changes due to calciphylaxis were compared with those of control rat subdermal explants in 60-day studies. Increased polyurethane mineralization was observed due to calciphylaxis with 60-day rat subdermal explants of Biomer ${ }^{\circledR}$, Mitrathane ${ }^{\circledR}$, and PEU-2000 (calcium levels, respectively, $4.13 \pm 0.56,18.61 \pm 2.73$, and $3.37 \pm 0.22 \mu \mathrm{g} / \mathrm{mg}$, mean \pm standard error) as compared to control explants (calcium levels, respectively, $1.22 \pm 0.1,12.57 \pm 0.86$, and $0.20 \pm 0.86$ $\mu \mathrm{g} / \mathrm{mg}$ ). The study also demonstrated that with 60 -day implants calciphylaxis had no side effects on somatic growth and serum calcium levels. Explant surface morphology of these polyurethane explants examined by scanning electron microscopy, back scattering electron imaging coupled with energy dispersive $X$-ray spectroscopy, and light microscopy demonstrated the presence of predominantly surface-oriented calcification. PEU-100, derivatized with 100 n.moles/ mg of EHBP, resisted calcification with explant calcium levels $0.51 \pm 0.01$ (calciphylaxis) and $0.38 \pm 0.01$ (control) $\mu \mathrm{g} / \mathrm{mg}$. It is concluded that calciphylaxis enhances superficial polyurethane calcification in rat subdermal implants and that an EHBP-modified polyurethane resists calcification despite calciphylaxis. Rat subdermal implants using calciphylaxis may be generally useful for evaluating the calcification potential of various biomedical polymers. (c) 1996 John Wiley \& Sons, Inc.

\section{INTRODUCTION}

Segmented polyurethane copolymers are frequently used to fabricate various blood-contacting device components, such as artificial heart- and cardiac-assist device bladders, trileaflet substitute heart valves, pacemaker lead insulation, and vascular grafts. ${ }^{1-3}$ However, the usefulness of these materials for long-term applications has been hampered by calcification..$^{4-8}$

Rat subdermal implants are useful for evaluating the calcification potential of glutaraldehyde pretreated bioprosthetic heart-valve tissues and other materials. ${ }^{9-13}$ However, previous rat subdermal implant studies using polyurethane have shown relatively little calcifica-

\footnotetext{
* To whom correspondence should be addressed at R-5014, Kresge II, The University of Michigan Medical School, Ann. Arbor, MI 48109.
}

tion $^{14-16}$ in contrast to the general tendency of this material to calcify in the circulation. ${ }^{4-8}$ Therefore, we have developed a novel rat subdermal model based on the phenomenon of vitamin-D enhanced calcification, known as calciphylaxis, ${ }^{17}$ for investigating the calcification of polyurethanes. Calciphylaxis has been broadly defined as "a condition of induced systemic hypersensitivity caused by the administration of a calcifying agent," such as dihydrotachysterol, a vitamin-D ana$\log .{ }^{17}$ The mechanism of calciphylaxis has been hypothesized to be due to transient local and systemic increases of serum calcium and phosphate levels. ${ }^{17}$

The objectives of this study were 1) using rat subdermal implantation to evaluate the effects of dihydrotachysterol-induced calciphylaxis on the calcification of polyurethanes; 2) to characterize the morphology of polyurethane calcification with and without calciphylaxis; and 3) to assess the calcification 
resistance of a polyurethane containing covalentlylinked ethanehydroxybisphosphonate (EHBP).

\section{MATERIALS AND METHODS}

\section{Materials}

Biomer ${ }^{\circledR}$ (Ethicon, Somerville, NJ), Mitrathane ${ }^{\circledR}$ (Polymedica, Denver, CO), and PEU-2000 (CarboMedics, Austin, TX) medical-grade polyurethanes were used as received. Bulk PEU-2000, modified by covalently bound EHBP (100 $\mathrm{nM} / \mathrm{mg}$ ), was designated as PEU-100. ${ }^{18}$ Dihydrotachysterol (Sigma, St. Louis, MO) and $100 \%$ pure Mazola corn oil (Best Foods, CPC International Inc., Englewood Cliffs, NJ) were used as received. All solvents used during the experiment (Aldrich Chem., Milwaukee, WS) were anhydrous and were used without any further purification.

The test polymer films were prepared as follows: Biomer ${ }^{\circledR}$ and Mitrathane ${ }^{\circledR}$ films were cast by diluting the original $25 \% \mathrm{~N}, \mathrm{~N}$-dimethylacetamide (DMAc) solution to approximately $10 \%$ by using anhydrous DMAc. Ten percent PEU-2000 and PEU-100 solutions were prepared in anhydrous tetrahydrofuran. Each polymer solution was then poured onto Teflon plates (Cole Parmer, Chicago, IL) and formed as thin sheets $(0.035 \pm 0.0038 \mathrm{~cm}$ thick) by evaporating the solvent under vacuum. After $48 \mathrm{~h}$ of drying time, the films were cut into $1 \mathrm{~cm}^{2}$ pieces. Each sample was annealed at $125^{\circ} \mathrm{C}$ under vacuum for $1 \mathrm{~h}$ to remove any residual internal stress.

\section{Animal model}

\section{Dihydrotachysterol sensitization}

Four-week-old rats (140-150 g) (CD Sprague Dawley, Charles River Laboratories, Burlington, MS) were divided randomly into two groups (4 rats/group). On the first day of the experiment, the calciphylaxis group of rats was administered $1 \mathrm{mg}$ dihydrotachysterol dissolved in $1.0 \mathrm{~mL}$ of corn oil. The dihydrotachysterol solution was injected directly into the rat's stomach through an oral gastric tube according to the procedure described by Selye. ${ }^{77}$ Rats not receiving dihydrotachysterol were used as controls.

\section{Subdermal implantation and retrieval}

The rats were anesthetized using ketamine (ParkDavis, Morris Plains, NJ, $0.057 \mathrm{mg} / \mathrm{g}$ ) and xylazine (Haver, Shawnee, KS, $0.008 \mathrm{mg} / \mathrm{gm}$ ), weighed, and the polyurethane films to be tested were implanted subcutaneously in all of the groups of rats. ${ }^{18}$ Polyure- thane samples were implanted into the anesthetized rats in subcutaneous pouches dissected in the ventral abdominal wall. Following recovery, the animals were maintained on Lab Chow (Ralston-Purina, St. Louis, $\mathrm{MO}$ ). At the end of 60 days after implant, the animals were anesthetized (as above), weighed, and blood was collected by cardiac puncture before they were killed. The retrieved polyurethane samples were rinsed with saline and dried thoroughly before characterizing them for chemical analyses and surface properties. At necropsy, femurs were retrieved and fixed in neutral buffered formalin for an assessment of side effects on bone.

\section{Characterization}

From each group representative samples were prepared for scanning electron microscopy/energy dispersive $X$-ray spectroscopy analyses by incubating them with $0.6 \%$ pepsin (Sigma, St. Louis, MO, pH 3.4, in double-distilled water) for $24 \mathrm{~h}$ so as to remove surface adsorbed proteinaceous debris. ${ }^{15,16}$ The changes in the surfaces of the samples were evaluated by comparison with pepsin-incubated unimplanted controls. For light microscopic and chemical analyses the explanted samples were analyzed without pepsin treatment. Thirteen explanted samples per formulation were used for total calcium and phosphorous, and the mean results were reported. Three representative samples per formulation were used for scanning electron microscopy/energy dispersive $\mathrm{X}$-ray spectroscopy and microscopic analyses.

\section{Calcium and phosphate analysis}

The unimplanted and explanted samples dried to constant weight were analyzed for total calcium and phosphorus by hydrolyzing samples in $6 \mathrm{~N} \mathrm{HCl}$ for $24 \mathrm{~h}$ at $70^{\circ} \mathrm{C}$. The total calcium levels were determined on aliquots of the acid hydrolysates using a PerkinElmer 2380 atomic absorption spectroscopy system (Perkin-Elmer, Norwalk, CT) as previously described..$^{10}$ An ammonium molybdate-complexation phosphorus assay was carried out on separate aliquots of the acid hydrolysates. ${ }^{19}$

Scanning electron microscopy and energy dispersive X-ray spectroscopy

Air-dried surfaces of the unimplanted and explanted samples were sputter coated with graphite under vacuum. A $1.5 \times 10^{-5}$ torr vacuum with a current density of $20 \mathrm{~mA}$ and $1500 \mathrm{~V}$ was used to develop an approximately $15 \mathrm{~nm}$ thick layer of graphite coating. Samples were then characterized by scanning electron microscopy (Hitachi Model S-570, Santa Clara, CA) and energy dispersive $X$-ray spectroscopy (Kevax-8000, Foster City, CA) for calcium and phosphorus. 
Light microscopy

Representative explanted samples from both calciphylaxis and control groups were fixed with neutral buffered formalin and embedded in glycolmethacrylate (JB-4 Polyscience, Warrington, PA) using previously described methods. ${ }^{10}$ Sections were cut at 2 $3 \mu \mathrm{m}$ with glass knives and stained with hematoxylin and eosin (for overall morphology) and with von Kossa's reagent (for calcium phosphate).

\section{Data analysis}

Numerical results were expressed as means \pm standard errors of the means. Differences between groups were assessed using the unpaired Student $t$ test for comparisons. Results were termed significant for $p<$ 0.05 .

\section{RESULTS}

\section{Effects of calciphylaxis on polyurethane calcification}

At explant, polyurethane samples were dissected free of typically thin fibrous capsules. These capsules were not observed to be grossly calcified and were not further assessed for mineralization. Polyurethane samples (without EHBP) explanted from calciphylaxis animals demonstrated no gross calcific deposits, but they had significantly increased total levels of calcium (two fold or greater) and phosphorus in comparison to explants from control rats (see Table I). The EHBPmodified polyurethane (PEU-100) demonstrated virtually no calcium accumulation despite calciphylaxis, however, it had measurable phosphorus levels, not differing from unimplanted samples, likely reflecting phosphorus associated with the bound EHBP.

Average weight gains and serum calcium levels of the rats used in these studies were not significantly affected by calciphylaxis. The calciphylaxis rats gained an average of $169.6 \pm 5.87 \mathrm{~g}$ (mean \pm standard error), whereas the mean weight gain of the controls was $181.4 \pm 7.85 \mathrm{~g}$ after 60 days. The serum calcium levels at the time of sacrifice also were found to be unaffected by calciphylaxis, $\mathrm{Ca}^{2+} 10.5 \pm 0.3 \mathrm{mg} / \mathrm{dL}$, compared to controls, $\mathrm{Ca}^{2+} 10.9 \pm 0.4 \mathrm{mg} / \mathrm{dL}$. Thus the calciphylaxis-induction dosage protocol had no apparent side effects on growth and serum calcium levels.

\section{Effects of calciphylaxis on the morphology of mineral deposits}

Polyurethane explant calcification was typically surface oriented for all the materials studied, as illustrated for the 60-day PEU-2000 calciphylaxis explanted samples [Fig. 1(A,B)]. These explants showed a rough and uneven surface morphology with a heavy encrustation occupying more than $80 \%$ of the total exposed surface. The surface deposits proved to be thick layers of calcium phosphate, as confirmed by the back scattering electron image and energy dispersive X-ray spectroscopy (Fig. 1). However, scanning electron microscopy showed virtually no calcification of the explants (calciphylaxis) of PEU-100, [see Fig. 1(C,D)], the EHBPderivatized polyurethane. Phosphorous, though, was detected on the surface of the PEU-100 explants and may be accounted for by the EHBP derivatization (as described above).

Light microscopic examination of Biomer ${ }^{\circledR}$ and Mitrathane ${ }^{\circledR}$ calciphylaxis and control explants [see Fig. 2(A-F)] confirmed the quantitated calcium levels and the superficial distribution of calcific deposits.

TABLE I

Enhanced Calcification of Polyurethane Rat Subdermal Implants with Calciphylaxis: Calcification Resistance with EHBP

\begin{tabular}{|c|c|c|c|c|c|}
\hline Implant Material & $\mathrm{N}$ & Calciphylaxis & $\mathrm{Ca}^{2+} \mu \mathrm{g} / \mathrm{mg}$ & $\mathrm{PO}_{4}^{3-} \mu \mathrm{g} / \mathrm{mg}$ & $\begin{array}{c}\mathrm{Ca}^{2+} / \mathrm{PO}_{4}^{3-} \\
\text { (Molar Ratios) }\end{array}$ \\
\hline Unimplanted Biomer & 4 & -- & $0.15 \pm 0.09$ & $0.03 \pm 0.01$ & - \\
\hline Biomer control & 17 & No & $1.29 \pm 0.51$ & $0.84 \pm 0.29$ & 1.18 \\
\hline Biomer & 19 & Yes & $4.13 \pm 0.56^{*}$ & $2.58 \pm 0.30^{*}$ & 1.24 \\
\hline Unimplanted Mitrathane & 4 & -- & $0.15 \pm 0.11$ & $0.21 \pm 0.01$ & - \\
\hline Mitrathane control & 20 & No & $10.73 \pm 1.42$ & $8.30 \pm 1.42$ & 0.99 \\
\hline Mitrathane & 19 & Y'es & $18.61 \pm 0.73^{*}$ & $11.39 \pm 1.14^{*}$ & 1.26 \\
\hline PEU-2000 unimplanted & 4 & - & $0.34 \pm 0.10$ & $0.01 \pm 0.09$ & - \\
\hline PEU-2000 control & 19 & No & $0.00 \pm 0.00$ & $0.00 \pm 0.00$ & - \\
\hline PEU-2000 & 19 & Y'es & $3.37 \pm 0.22^{*}$ & $1.98 \pm 0.01^{*}$ & 1.31 \\
\hline PEU-100 unimplanted ${ }^{\dagger}$ & 4 & - & $0.11 \pm 0.01$ & $1.52 \pm 0.09$ & - \\
\hline PEU-100 control ${ }^{\dagger}$ & 19 & No & $0.38 \pm 0.01$ & $2.05 \pm 0.84$ & 0.14 \\
\hline PEU-100 & 19 & Y'es & $0.52 \pm 0.09$ & $1.98 \pm 0.02$ & 0.20 \\
\hline
\end{tabular}

${ }^{*} p<0.001$ calciphylaxis vs. control implant.

${ }^{+}$Containing covalently linked EHBP. 

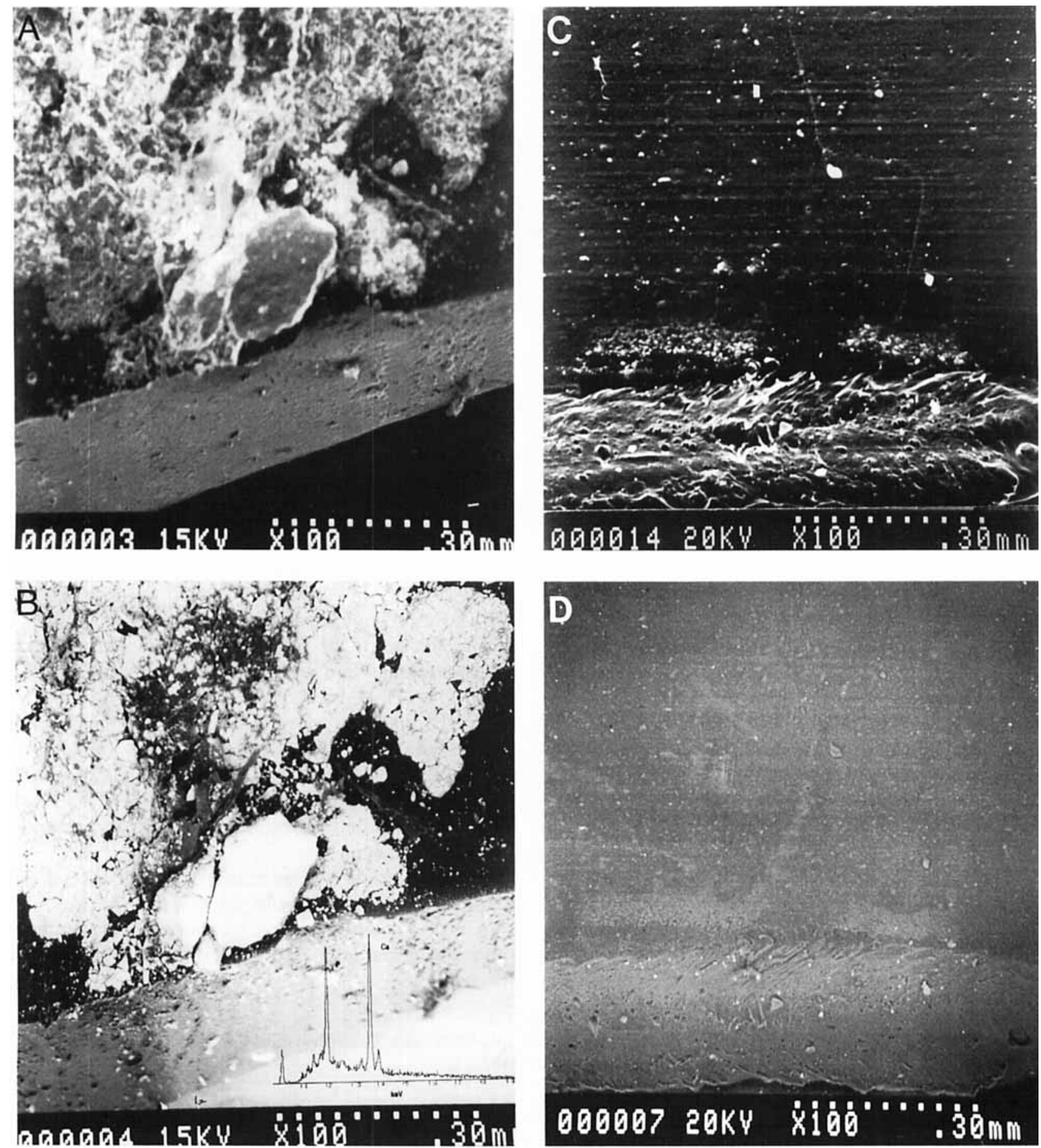

Figure 1. Scanning electron microscopic image and back scattering electron images of explants (calciphylaxis) PEU-2000 and PEU-100 (EHBP-derivatized): (A), scanning electron micrograph of an explanted PEU-2000 calciphylaxis sample demonstrating surface encrustation; (B), back-scattering electron image of the same explanted PEU-2000 calciphylaxis samples (B, insert spectra) confirming $\mathrm{Ca}^{2+}$ and $\mathrm{PO}_{4}^{3-} ;(\mathrm{C})$, scanning electron micrograph of an explanted PEU-100 calciphylaxis sample showing no encrustation; (D), back-scattering electron image of explanted PEU-100 calciphylaxis sample.

Morphologically observable calcification could not be found on the Biomer ${ }^{\circledR}$ control [Fig. 2(A)] implant. However, Biomer ${ }^{\circledR}$ calciphylaxis implants [Fig. $2(B, C)]$ showed multifocal, thin surface layers of calcific deposits at the polymer surfaces. As illustrated in Figure 2(D-F), the most heavily calcified explants were in the Mitrathane ${ }^{\circledR}$ group (particularly with calciphylaxis). Mitrathane ${ }^{\circledR}$ controls [Fig. 2(D)] generally had qualitatively less calcification than the corresponding calciphylaxis samples. Although the calcification observed in the present study was at the polyurethane surfaces, a lesser, immediately subsurface component of mineralization also appeared to be characteristic of Mitrathane ${ }^{\circledR}$, particularly in the 

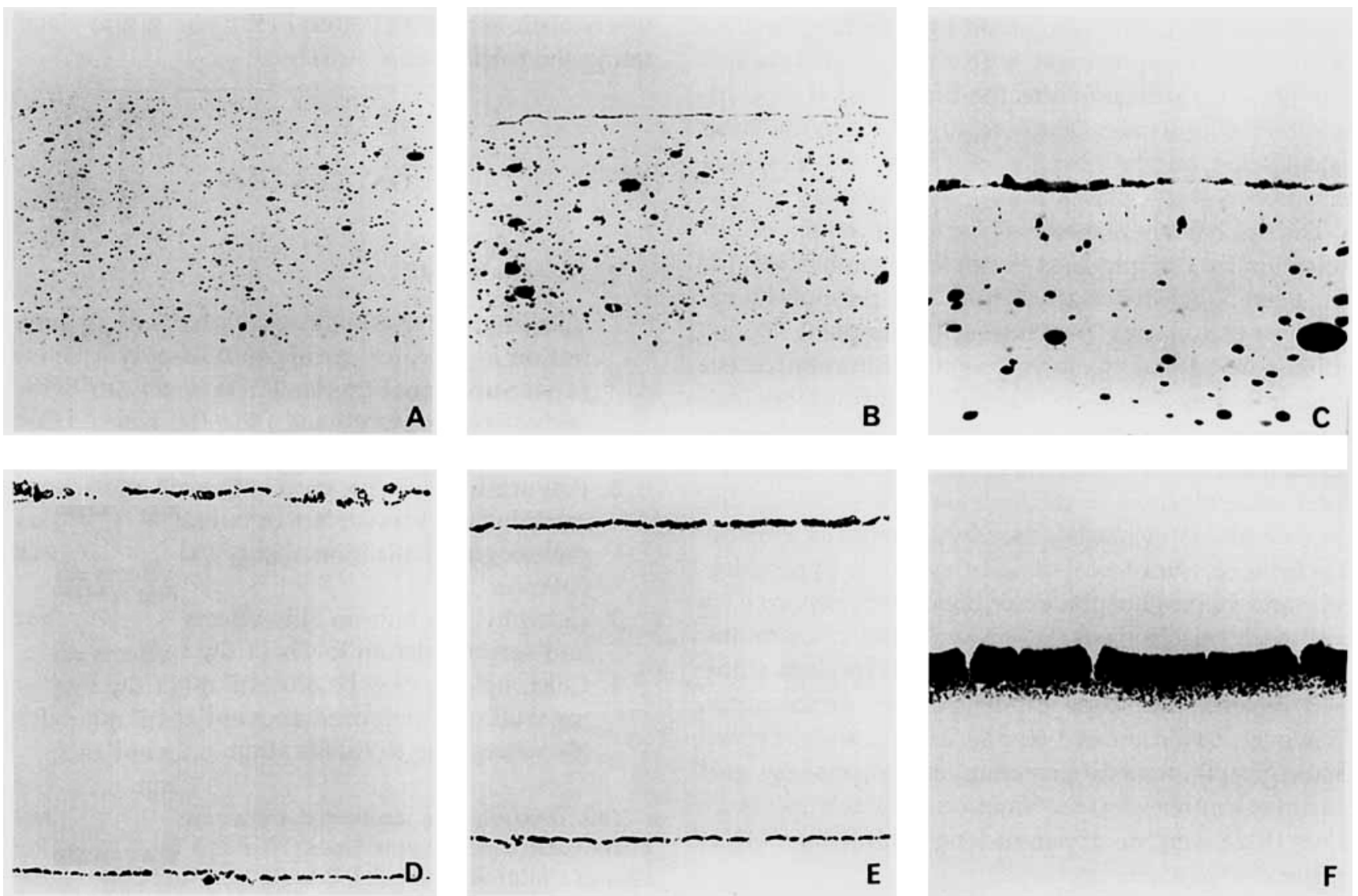

Figure 2. Light microscopic morphology of polyurethane-associated calcification, without and with calciphylaxis: (A,B,C), Biomer $B$ without calciphylaxis, with calciphylaxis, and high-power with calciphylaxis, respectively. Calcification is limited to the polymer surface. The dark ovoid structures in the bulk polymer are characteristic of this polyurethane formulation, present prior to implantation, and are unrelated to calcification. (D,E,F), Mitrathane ${ }^{\circledR}$ without calciphylaxis, with calciphylaxis,

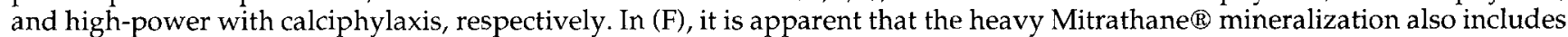
an immediately subsurface component. All stained with von Kossa's reagent (calcium phosphates black); original magnification $A, B, D$, and $E 75 \times ; G$ and $F 300 \times$.

calciphylaxis animals [Fig. 2(F)]. Whether this was related to the heavy degree of calcification per se or to some other specific feature of this polymer is presently undetermined.

\section{DISCUSSION}

Our studies have demonstrated that dihydrotachysterol-induced calciphylaxis enhances polyurethane calcification in rat subdermal implants. The specific principal findings of these investigations were:

1. Calcification of polyurethane subdermal explants was significantly enhanced due to calciphylaxis compared to control. Calcium and phosphorous levels in calciphylaxis explants were approximately two-fold or more greater than in controls. However, our EHBP-derivatized polyurethane, PEU-100, did not calcify despite calciphylaxis.

2. Scanning electron microscopy, energy dispersive $\mathrm{X}$-ray spectroscopy, and light microscopy analy- sis of the calciphylaxis explants (except for PEU100 ) demonstrated the predominant surface orientation of calcification.

3. Calciphylaxis did not adversely affect the average somatic growth and serum calcium levels of the rats by the conclusion of the implant period.

In vitro model systems of polyurethane calcification have been investigated by a number of groups ${ }^{20-22}$ as models of this disease process. Although many have attempted to duplicate physiologic conditions by using serum incubations and various material stress conditions, none of these in vitro studies has resulted in a morphology approximating polyurethane calcification in vivo. This may be due in part to a general failure in the prior studies to maintain constant composition conditions with respect to calcium and phosphorous. ${ }^{24}$ Furthermore, prior subdermal implant studies ${ }^{14-16}$ have demonstrated, in general, relatively little polyurethane calcification in comparison to the present results using calciphylaxis. However, these prior subdermal studies, despite not using calciphylaxis, demonstrated surface- 
oriented calcific deposits, noted by scanning electron microscopy, in agreement with the present results. ${ }^{16}$ The present study provides the first detailed description of the light microscopy features of polyurethane calcification, in the absence of conditions in which thrombosis could play a role.

The mechanism responsible for enhancement of calcification by calciphylaxis is not well established. ${ }^{16} \mathrm{It}$ has been suggested that calciphylaxis promotes a reactive inflammatory response at the implant site resulting in cellular necrosis due to infiltration of eosinophills and pseudoeosinophills. ${ }^{17}$ Furthermore, calciphylaxis studies done by Selye et al. ${ }^{17}$ and other researchers ${ }^{25-29}$ have demonstrated that transiently the local concentration of calcium and phosphate at the implant site is increased, thus hypothetically enhancing local calcification. Transient systemic hypercalcemia and hyperphosphatemia have been reported as well with calciphylaxis. ${ }^{77,25-29}$ Monitoring calcium metabolism throughout the course of our implant study was beyond the scope of the present experiments. However, based on our 60-day explant data, net somatic growth, femoral growth plate morphology, and serum calcium levels were unaffected by calciphylaxis. Thus there were no apparent long-lasting side effects of the calciphylaxis protocol.

The pathobiology of polymer calcification is presently uncertain. Nucleation clearly occurs at and adjacent to the polymer surface in areas devoid of cells. Furthermore, the fibrous capsule surrounding the implant did not appear to grossly influence the calcification in the present studies. Thoma and Phillips have hypothesized that mineralization of polyetherurethane may be due to metal ion complexation by the polyurethane soft segment. ${ }^{30}$ However, there is little evidence to support this. Other hypotheses consider adsorptive events involving cell debris, lipid, and protein uptake, as well as thrombus-related calcification in some cases. ${ }^{4-8}$ Although the present results provide no information concerning thrombus-oriented calcification, further studies concerning adsorptive mechanisms may be facilitated using our calciphylaxis model of polyurethane calcification.

Previous work from our group had demonstrated that coatings using our EHBP-derivatized polyurethane (PEU-100) without calciphylaxis prevented Mitrathane calcification in rat subdermal implants. ${ }^{16}$ The present results confirmed the calcification resistance of PEU-100 using calciphylaxis. The EHBP bound within PEU-100 has been demonstrated to be irreversibly covalently linked ${ }^{16}$ and may inhibit calcification in part due to diminished calcium diffusion. EHBP and bisphosphonates in general are well-known inhibitors of calcification in vitro due to inhibition of calcium phosphate nucleation and crystal growth. ${ }^{31}$ Both of these mechanistic actions of bound EHBP also may be facilitating the calcification resistance.

\section{CONCLUSIONS}

We conclude that:

1. Calciphylaxis due to dihydrotachysterol administration aggravates calcification of polyurethanes in rat subdermal implants. However, an EHBPderivatized polyurethane, PEU-100, resisted calcification despite calciphylaxis.

2. Polyurethane calcification both with and without calciphylaxis was surface oriented, comparable to pathologic calcification of polyurethane in the circulation.

3. Calciphylaxis had no side effects on the growth and serum calcium levels of the rats.

4. Calciphylaxis may be a useful adjunct to screening studies of polyurethanes and other biomaterials susceptible to calcification.

This research was supported by a research grant from CarboMedics Inc., Austin, Texas. We thank Dr. Melvin Glimcher of Children's Hospital, Boston, MA, for his helpful advice concerning calciphylaxis. The authors also wish to thank Dr. Xuan Qu, Shimul Shah, Hugh Pabarue, Christopher Lee, Sara Murray, and Helen Shing for their technical assistance.

\section{References}

1. M. D. Lelah and S. L. Cooper, "Polyurethane bloodcontact devices," in Polyurethanes in Medicine, M. D. Lelah and S. L. Cooper (eds.), CRC Press, Boca Raton, Florida, 1986, pp. 159-166.

2. M. Szycher, "Hemocompatible interfaces in artificial heart devices," in High Performance Biomaterials: A Comprehensive Guide to Medical and Pharmaceutical Applications, M. Szycher (ed.), Technomic Publishing Co., Lancaster, Pennsylvania, 1991, pp. 103-164.

3. M. Szycher, "An assessment of elastomers for biomedical applications," in Biocompatible Polymers, Metals, and Composites, M. Szycher (ed.), Technomic Publishing Co., Lancaster, Pennsylvania, 1983, pp. 103-164.

4. H. Harasaki, R. Gerrity, R. Kirlay, G. Jacobs, and Y. Nose, "Calcification in blood pumps," Trans. Am. Soc. Artif. Intern. Org., 25, 305-310 (1979).

5. R. L. Whalen, J. L. Snow, H. Harasaki, and Y. Nose, "Mechanical strain and calcification in blood pumps," Trans. Am. Soc. Artif. Intern. Org., 26, 487-492 (1980).

6. D. Coleman, "Mineralization of blood pump bladders," Trans. Am. Soc. Artif. Intern. Org., 27, 708-713 (1981).

7. S. L. Hilbert, V. J. Ferrans, Y. Tomita, E. E. Eidbo, and M. Jones, "Evaluation of explanted polyurethane trileaflet cardiac valve prostheses," J. Thorac. Cardiovasc. Surg., 94, 419-429 (1987).

8. T. Akutsu, B. Dreyer, and W. J. Kolff, "Polyurethane artificial heart valves in animals," J. Appl. Physiol., 14, 1045-1048 (1985). 
9. R. J. Levy, F. J. Schoen, J. T. Levy, A. C. Nelson, S. L Howard, and L. J. Oshry, "Biologic determinants of dystrophic calcification and osteocalcin deposition in glutaraldehyde-preserved porcine aortic valve leaflets implanted subcutaneously in rats," Am. J. Pathol., 113, 143-155 (1983).

10. F. J. Schoen, J. W. Tsao, and R. J. Levy, "Calcification of bovine pericardium used in cardiac valve bioprosthesis: Implication for the mechanism of bioprosthetic tissue mineralization," Am. J. Pathol., 123, 34-144 (1986).

11. R. J. Levy, J. Wolfrum, F. J. Schoen, M. A. Hawley, S. A. Lund, and R. Langer, "Inhibition of calcification of bioprosthetic heart valves by local controlled-release bisphosphonate," Science, 228, 190-192 (1985).

12. G. Golomb and V. Ezra, "Prevention of bioprosthetic heart valve calcification by charge modification: Effects of protamine binding by formaldehyde," J. Biomed. Res. 25, 85-98 (1991).

13. M. C. Fishbein, R. J. Levy, V. J. Ferrans, L. C. Dearden, A. Nashef, A. P. Goodman, and A. Carpenter, "Calcification of cardiac valve bioprosthesis. Biochemical, histologic, and ultrastructural observations in subcutaneous implantation model system," J. Thorac. Cardiovasc. Surg., 83, 602-609 (1982).

14. G. Golomb, "Calcification of polyurethanes based biomaterials implanted subcutaneously in rats: Role of porosity and fluid absorption in the mechanism of mineralization," J. Mater. Sci.: Mater. in Med., 2, 272-277 (1992).

15. J. R. Frautschi, J. R. Chinn, R. E. Phillips, Jr., Q. Zhao, J. M. Anderson, R. R. Joshi, and R. J. Levy, "Degradation of polyurethanes in vivo: Evaluation of several models," Coll. and Surface: Biointerfaces, 1, 305-313 (1993).

16. R. R. Joshi, J. R. Frautschi, R. E. Phillips, Jr., and R. J. Levy, "Phosphonated polyurethanes that resist calcification," J. Appl. Biomater., 5, 65-67 (1994).

17. H. Selye, "Topical calciphylaxis," in Calciphylaxis, C. F. McLean (ed.), The University of Chicago Press, Chicago, 1962, pp. 37-51.

18. R. J. Levy, "Calcification-resistant biomaterials," U.S. Patent No. 5, 296, 583, March 22, 1994.

19. P. S. Chen, T. Y. Toribira, and H. Warner, "Micro determination of phosphorus," Anal. Chem., 28, 1756-1758 (1956).

20. B. Glasmacher-Seiler, H. Reul, G. Rau, and G. Weiland, "In vitro investigation of the calcification behavior of polyurethane biomaterials," in Polyurethanes in Biomedi- cal Engineering II, H. Planck, I. Syre, M. Damner, and G. Egbers (eds.), Elsevier Science Publishers, Amsterdam, 1987, pp. 151-168.

21. R. Marchant, A. Hiltner, C. Hamlin, A. Rabinovitch, R. Slobodkin, and J. M. Anderson, "In vivo biocompatibility studies. I. The cage implant system and a biodegradable hydrogel," J. Biomed. Mater. Res., 17, 301-325 (1983).

22. G. Golomb and D. Wagner, "Development of a new in vitro model for studying implantable polyurethane calcification," Biomaterials, 12, 397-405 (1991).

23. L. H. G. Woulers, E. P. M. Rousseall, A. A. Van Steenhoven, and A. L. German, "An experimental set up for the analyses of polyurethane calcification," in Polyurethanes in Biomedical Engineering II, H. Planck, I. Syre, M. Damner, G. Egbers (eds.), Elsevier Science Publishers, Amsterdam, 1987, pp. 169-181.

24. G. H. Nancollas and S. J. Zawacki, "Calcium phosphate mineralization," Connect. Tiss. Res., 21, 239-246 (1984).

25. S. Grasso and H. Selye, "Calciphylaxis in relation to the humoral production of occlusive coronary lesions with infarction," J. Path. Bact., 83, 495-501 (1973).

26. S. Noda and M. Mori, "Experimental calcification in rat submandibular glands," Cell. Mol. Biol., 38, 413-427 (1992).

27. I. Y. Rosenblum, H. E. Black, and J. F. Ferrell, "The effect of various bisphosphonates on a rat model of cardiac calciphylaxis," Calcif. Tissue Res., 23, 151-159 (1977).

28. M. J. Glimcher, B. Reit, and D. Kossiva, "Serine phosphate, threonine phosphate and $\gamma$-carboxyglutamic acid in normal and experimentally induced, pathologically calcified rat skin (topical calciphylaxis)," Calcif. Tissue Int., 33, 185-190 (1981).

29. I. Y. Rosenblum, L. Flora, and R. Einstein, "The effect of disodium ethane-hydroxy-1 1-bisphosphonate (EHBP) on a rabbit model of athero-arteriosclerosis," Atherosclerosis, 22, 411-424 (1975).

30. R. J. Thomas and R. E. Phillips, "Metal ion complexation of polyurethanes. A proposed mechanism of calcification," in Polyurethanes in Biomedical Engineering II, H. Planck, I. Syre, M. Damner, and G. Egbers (eds.), Elsevier Science Publishers, Amsterdam, 1987, pp. 185-190.

31. H. Fleisch, "Bisphosphonates: History and mechanism of action," Metabol. Bone Dis. Rel. Res., 3, 279-287 (1981).

Received February 6, 1995

Accepted September 21, 1995 